\title{
EVOLUÇÃO DA BASE DE CONHECIMENTOS EM BIOPRODUTOS E \\ BICOMBUSTÍVEIS DE GERAÇÃO AVANÇADA: UMA ANÁLISE DE REDES \\ SOCIAIS A PARTIR DE DOCUMENTOS DE PATENTE
}

Área Temática ABEIN: Área 5; Classificação JEL: O30: Innovation • Research and Development • Technological Change • Intellectual Property Rights; Subcategoria O30: General

Palavras-chave: bioprodutos e biocombustíveis avançados; base de conhecimentos; análise de redes sociais

Autor: Guilherme de Oliveira Marques (doutorando)

Departamento de Política Científica e Tecnológica (DPCT), IG / UNICAMP

Resumo

O desenvolvimento da produção de biocombustíveis e de bioprodutos de geração avançada guarda um enorme potencial. Esta indústria, no entanto, tem enfrentado sérios desafios, especialmente no que se refere ao escalonamento das suas tecnologias de processo. O 'vale da morte' existente entre uma grande ideia, demonstrada em escala laboratorial e validada em plantas pilotos, e a sua exploração industrial ainda subsiste como um enorme obstáculo que muitas empresas não conseguem transpor.

A superação destes desafios depende da incorporação de novos conhecimentos e da construção de novas capacidades, que alicercem a concepção de soluções tecnológicas renovadas, condizentes à complexidade dos desafios existentes.

Este trabalho pretende analisar, a partir da aplicação do ferramental do método Análise de Redes Sociais (ARS), a evolução da base de conhecimentos para desenvolvimento da produção de renováveis avançados ao longo dos últimos 46 anos (1970-2016). A sua principal contribuição reside na tentativa de vincular esta dinâmica ao padrão setorial de inovação e ao direcionamento das estratégias tecnológicas das empresas. 


\section{Introdução}

O estabelecimento de uma nova indústria, pautado no desenvolvimento e na difusão de tecnologias radicalmente novas, é um processo lento, árduo e altamente incerto. As novas tecnologias por detrás deste surgimento frequentemente requerem grandes investimentos em melhorias, maturação e demonstração de sua viabilidade antes de atingirem uma relação custo/desempenho capaz de sustentar a sua introdução comercial. Fatores do "ambiente" no qual as firmas operam condicionam este processo de diferentes maneiras, seja encorajando ou desestimulando investimentos, seja influenciando a sua velocidade e direção. Este é um processo permeado por idas e vindas, por tentativas, erros e acertos.

A indústria de biocombustíveis e bioprodutos de geração avançada guarda um enorme potencial de desenvolvimento baseado em soluções inovativas, tanto em termos da criação de produtos ambientalmente mais sustentáveis, como novos materiais, compostos químicos e combustíveis, como para a geração de emprego e renda.

Esta indústria, no entanto, tem enfrentado sérios desafios à sua expansão e consolidação, relacionados tanto a fatores endógenos à sua operação - como o escalonamento das suas principais tecnologias, como a fatores que pertencem ao "ambiente", no que se destaca a dinâmica recente do mercado de petróleo e de gás natural ${ }^{1}$. O 'vale da morte' existente entre uma grande ideia, demonstrada em escala laboratorial e validada em plantas pilotos, e a sua exploração industrial ainda subsiste como um enorme obstáculo que muitas empresas não conseguem transpor.

A superação destes desafios só poderá ocorrer através da absorção de novos conhecimentos e da construção de novas capacidades, aptas a alicerçar a geração de soluções tecnológicas renovadas e vigorosas, com viabilidade comercial demonstrável capaz de justificar os investimentos necessários ao seu desenvolvimento e à sua difusão.

Este panorama tem se desdobrado em diferentes movimentos. Algumas empresas cujo foco inicial era a produção industrial de biocombustíveis têm redirecionado esforços para o desenvolvimento de novas aplicações comerciais, como especialidades químicas, nutracêuticos ou produtos para alimentação animal. Outras, centradas ainda nos biocombustíveis, têm remodelado seu pacote tecnológico de modo a lidar com dificuldades técnicas que não haviam sido antecipadas, em parte devido à natureza não sequencial do investimento necessário, em parte por excesso de otimismo ou falta de zelo. Esta readequação, no entanto, é ardilosa. O redirecionamento de estratégias tecnológicas exige esforços deliberados de aprendizado e a remodelação de dos recursos internos das empresas, cuja magnitude irá depender da distância cognitiva entre os conhecimentos requeridos para a estratégia adota no momento $t$ com relação à estratégia adotada em $t_{+1}$.

Estes movimentos não denotam o aniquilamento do desenvolvimento da produção de biocombustíveis avançados. Eles apenas refletem o reconhecimento por

\footnotetext{
${ }^{1}$ Segundo a U.S. Energy Information Administration (EIA), “North Sea Brent crude oil prices averaged $\$ 38 /$ barrel (b) in December (2015), a $\$ 6 / b$ decrease from November (2015), and the lowest monthly average price since June 2004. Brent crude oil prices averaged $\$ 52 / \mathrm{b}$ in 2015, down $\$ 47 / \mathrm{b}$ from the average in 2014, as growth in global liquids inventories downward pressure on Brent prices throughout much of the year" (EIA, 2016, pp. 1).
} 
algumas organizações de que há no momento oportunidades mais interessantes em alguns nichos de mercado, com produtos de baixo volume e altas margens, que podem servir como refúgio para a construção de capacidades que, em um cenário futuro mais favorável, permitam o desenvolvimento de tecnologias e modelos de produção mais eficientes para biocombustíveis, a partir do aprendizado obtido nestes novos mercados.

As empresas evoluem, em termos daquilo que podem fazer, a partir de um processo de aprendizado que modifica gradualmente a sua base de conhecimentos e de competências, e que é moldado por fatores endógenos e exógenos às suas fronteiras. Este é um movimento que tem origem no interior de cada organização, mas que possui um amplo alcance coletivo, que se traduz na alteração do conjunto de conhecimentos relevantes para a inovação em um setor ao longo do tempo.

Este trabalho busca analisar, a partir da aplicação do ferramental do método Análise de Redes Sociais (ARS), a evolução da base de conhecimentos para desenvolvimento da produção de renováveis avançados de 1970 a 2016. Nós buscaremos inferir se a estrutura da base de conhecimentos e a importância relativa dos diversos campos que a compõe têm se modificado desde a descoberta da tecnologia de DNA recombinante ${ }^{2}$ na década de 1970 até a atualidade. Buscaremos também compreender qual tem sido o padrão desta evolução, especialmente no que se refere à presença de descontinuidades tecnológicas. Dentro dos limites impostos pelo método escolhido, buscaremos relacionar esta dinâmica ao redirecionamento de estratégias de busca de algumas empresas.

Há na literatura trabalhos que vinculam a dinâmica da base de conhecimentos ao surgimento de novas oportunidades inovativas (KLEVORICK ET AL, 1995); à emergência de novos sistemas tecnológicos (ANTONELLI, KRAFFT E QUATRARO, 2010); e ao desempenho (SAVIOTTI, 2004; NESTA \& SAVIOTTI, 2005; TEECE et al, 1994) e diversificação de atividades produtivas (BRESCHI ET AL, 2003). Nesta pesquisa, pretendemos contribuir com este debate ao adicionar concretude à análise do processo de evolução da base de conhecimentos setorial, relacionando-a à dinâmica do padrão setorial de inovação e à estratégia tecnológica das empresas.

A base de conhecimentos aqui é compreendida como o conjunto de conhecimentos utilizado em atividades produtivas e inovativas. Embora possua algum grau de especificidade (SAVIOTTI, 2007), ela possui um caráter coletivo uma vez que: diferentes organizações compartilham objetivos oepracionais semelhantes; há indivisibilidade na produção do conhecimento; a produção do conhecimento frequentemente ocorre separadamente à sua utilização, ou seja, o conhecimento é produzido por uma instituição diferente daquela que o utiliza; e pelo conhecimento, ao menos em alguma medida, transbordar do agente que o produz para outros agentes, mesmo quando são adotadas medidas de proteção como o patenteamento. Devido ao seu caráter coletivo, é possível definirmos e estudarmos a base de conhecimento ao nível setorial (MALERBA \& ORSENIGO, 1997).

\footnotetext{
${ }^{2}$ A tecnologia do DNA recombinante, criada na década de 1970, é na verdade um conjunto de técnicas derivadas de disciplinas como Microbiologia, Bioquímica, Imunologia e Genética Microbiana, que permite mecanismos de replicação e expressão gênica, na determinação da sequência de um gene e consequentemente da proteína que ele codifica, ou no desenvolvimento de culturas microbianas capazes de produzir substâncias úteis tais como a insulina humana, hormônio de crescimento, vacinas e enzimas industriais em grandes quantidades. Fonte: Nascimento et al (2003).
} 
O padrão de desenvolvimento da base de conhecimentos é condicionado pelo padrão setorial de inovação. Em indústrias tecnologicamente imaturas, a base de conhecimentos tende a ter um caráter de grande generalidade, ou seja, a mesma base é utilizada para o desenvolvimento da produção de uma gama heterogênea de produtos. Conforme a indústria vá amadurecendo, e trajetórias tecnológicas sejam melhor definidas, a base de conhecimentos tende a passar por um processo de diferenciação e especialização, com adensamento da vinculação entre os campos que a compõe e aumento da sua complexidade (SAVIOTTI, 2004; KRAFFT et al, 2011).

No entanto, embora a base de conhecimentos sofra importantes alterações na sua estrutura e composição, espera-se que ela mantenha uma certa estabilidade ao longo do tempo, já que: a alteração é inerentemente custosa; as empresas tendem a preservar certo grau de coerência na diversificação das suas atividades; e porque o conhecimento é uma estrutura recursiva, ou seja, o novo conhecimento é construído, ao menos em parte, com base no conhecimento já existente. Neste sentido, a base de conhecimentos se modifica na maior parte do tempo apenas de forma gradativa e incremental. Neste processo, novos conhecimentos aumentam progressivamente a sua importância enquanto diminui o peso de áreas que vão se tornando obsoletas. Isto não significa, no entanto, que grandes rupturas não aconteçam, mesmo que infrequentemente, com profundos impactos sobre a estrutura e composição da base de conhecimentos.

A dinâmica acima descrita nos permite conceber a evolução do conjunto de conhecimentos relevantes para inovação como um movimento cíclico, marcado pela emergência de descontinuidades às quais se seguem longos períodos de avanços incremental que, embora de pequeno alcance quando considerados isoladamente, têm um profundo efeito cumulativo a longo prazo. Descontinuidades tecnológicas invariavelmente estão relacionada à emergência de novos campos do conhecimento, que frequentemente possuem uma distância cognitiva dos campos já existentes suficientemente grande para que as capacidades de absorção existentes nas empresas sejam inadequadas para a sua incorporação.

Joseph Schumpeter foi um dos economistas pioneiros no estudo do padrão industrial de inovação. O padrão que veio ser conhecido como Marco I schumpteriano, atribuído às ideias contidas no livro A Teoria do Desenvolvimento Econômico (1911), é marcado por um ambiente altamente dinâmico, com facilidade de entrada de novos agentes, pautada na geração e utilização de tecnologias de ruptura. Neste padrão, as atividades de busca têm natureza exploratória, ou seja, estão voltadas ao aproveitamento de novas oportunidades inovativas, o que frequentemente está relacionado à exploração de conhecimentos de fronteira. Já o padrão de inovação que fícou conhecido como Marco II schumpteriano, relacionado à sua obra Capitalismo, Socialismo e Democracia (1942), é marcado pela existência de fortes barreiras à entrada inovativa e pela prevalência de grandes organizações corporativas, com forte poder de mercado. Neste padrão, a competitividade é alicerçada na exploração e extensão (incremental) do estoque de conhecimento já acumulado, bem como na utilização de ativos complementares e competências em P\&D.

A dinâmica de avanço do conhecimento em cada um dos dois padrões schumpterianos é muito diferente. Enquanto no Marco I a maioria das estratégias de busca está pautada no aproveitamento de oportunidades tecnológicas que surgem a partir da geração e da incorporação de novos conhecimentos, frequentemente advindos de pesquisas acadêmicas, no marco II é mais comum que as oportunidades estejam 
relacionadas à exploração da recombinação entre campos do conhecimento que já façam parte da base de conhecimentos para inovação.

Com base na discussão até aqui desenvolvida, o objetivo central desta pesquisa será o de investigar as seguintes hipóteses:

i. $\quad$ Nos últimos 46 anos (1970-2016), a base de conhecimentos para desenvolvimento da produção de renováveis avançados sofreu um processo de amadurecimento, marcado por movimentos de adensamento e ganho de complexidade. Nas fases mais incipientes da indústria, a base de conhecimentos era composta por poucos campos de grande generalidade, ou seja, de utilização comum por um amplo espectro de atividades heterogêneas. Ao longo do tempo, novos conhecimentos foram sendo adicionados em substituição ou em complemento aos conhecimentos já existentes, e foram sendo criados nichos de especialização separados, que se mantiveram conectados, no entanto, por conhecimentos de uso comum.

ii. Esta base de conhecimento, no período proposto, foi marcada por infrequentes eventos de descontinuidade, aos quais se seguiram longos períodos de avanço incremental.

iii. Embora tenha sofrido mudanças fundamentais durante o período considerado, a estrutura da base de conhecimentos em renováveis avançados apresenta certa estabilidade, com a presença ubíqua de alguns campos em torno dos quais há uma dinâmica de aparecimento e desaparecimento de outros campos.

iv. A importância relativa dos diferentes campos que compõe a base de conhecimentos sofre importantes mudanças ao longo do tempo.

O restante do paper está constituído da seguinte maneira: na seção 2, apresentamos um estudo sobre a dinâmica de geração e a difusão do conhecimento tecnológico, destacando as suas características fundamentais; a seção 3 apresenta a metodologia proposta, ou seja, a Análise de Redes Sociais; a seção 4 traz os principais resultados obtidos; e, na seção 5, apresentamos a discussão sobre as contribuições que obtivemos na análise da evolução da base de conhecimentos em renováveis avançados.

\section{Propriedades da Geração e da Difusão do Conhecimento}

O estudo da evolução da base de conhecimentos de um setor demanda que, antes de tudo, sejamos capazes de entender como o próprio conhecimento evolui. Há duas propriedades fundamentais do conhecimento que nos auxiliam na compreensão do seu processo de criação e difusão pelo sistema econômico (Saviotti, 2004, 2007):

i. $\quad$ O conhecimento é uma estrutura co-relacional;

ii. O conhecimento é uma estrutura recursiva e interpretativa;

Como estrutura co-relacional, o conhecimento é formado pela inter-relação entre diversas variáveis observáveis, de modo a representar, ao menos parcialmente, $o$ ambiente externo. Por outro lado, por ser instrumento para o uso e interpretação da informação, e pelo seu caráter cumulativo, é uma estrutura recursiva e interpretativa, ou seja, os agentes, frente a um novo problema, tendem a combinar capacidades e 
"pedaços" de conhecimento que já possuem para a geração de uma nova solução. Estas propriedades permitem visualizar o conhecimento como uma estrutura em rede, formado por diversos campos (vértices) que estabelecem entre si relações de interdependência, ou vínculos (SAVIOTTI, 2004, 2007).

Como o conhecimento evolui a partir do estabelecimento de conexões entre diferentes variáveis, é de se esperar que exista um lapso temporal entre criação de novos vértices e o estabelecimento de novos vínculos que depende, em partes, da distância cognitiva entre os novos campos novos e os já existentes. Assim, o surgimento de uma descontinuidade em uma base de conhecimentos faz com que a conectividade geral entre os diversos campos que a compõe inicialmente caia. Com o passar do tempo, no entanto, os novos campos são incorporados às rotinas produtivas e inovativas e passam a ser utilizados em conjunto com os demais, fazendo com que a conectividade da base volte a crescer (KRAFT ET AL, 2011).

Esta representação do conhecimento é compatível com a análise de Kuhn sobre a evolução da ciência (KUHN, 1962). Novas variáveis - ou novos campos científicos são criadas quando um novo paradigma emerge e, como estes novos campos ainda não interagiram com os demais, isto leva a uma queda de conectividade geral do sistema. Já na fase subsequente - a fase de ciência normal - ocorre o estabelecimento de novos vínculos entre os novos campos, e entre estes e os que já existiam. Isto, por sua vez, leva ao crescimento da conectividade que tende, então, a oscilar em torno de determinado valor ao longo do tempo. O mesmo entendimento pode ser aplicado à geração de novo conhecimento tecnológico e ao seu desenvolvimento incremental subsequente (KRAFT ET AL, 2012; DOSI, 1988).

A evolução do conhecimento então ocorre pela criação de novas fronteiras e de novos subconjuntos de relações entre diferentes campos. Pode-se esperar que a evolução de uma base de conhecimentos siga um processo no qual: i) novos conceitos e variáveis emergem; ii) alguns conceitos e variáveis velhos são extintos; iii) novas conexões são estabelecidas, fazendo surgir novos vínculos; iv) o peso relativo de novos e velhos campos e vínculos se altera ao longo do tempo (SAVIOTTI, 1996).

Assim, a instabilidade na rede surge como instabilidade nos vínculos existentes e pode ser interpretada como a falência das regras dominantes que permite a exploração de novos subconjuntos do ambiente externo e a criação de inovações.

\section{Metodologia}

Conceber o conhecimento como uma estrutura em rede nos permite utilizar ferramentas para a análise da dinâmica de redes para estudar a evolução da base de conhecimentos em renováveis avançados ao longo do tempo, desde que sejamos capazes de identificar as unidades (ou campos) do conhecimento e a sua interação.

A metodologia proposta para esta pesquisa - aplicação do ferramental da Análise de Redes Sociais (ARS) à apreciação da dinâmica evolutiva do conhecimento - foi inspirada em uma série de trabalhos de alguns pesquisadores da economia do conhecimento, em especial de autores como Pier Paolo Saviotti, Jackie Krafft, Francesco Quatraro e Cristiano Antonelli (SAVIOTTI, 2004, 2007, 2009; ANTONELLI, KRAFFT \& QUATRARO, 2010; KRAFFT, QUATRARO \& SAVIOTTI 2011; QUATRARO, 2009). 
O uso do ferramental de Análise de Redes Sociais (ARS) é um caminho promissor para uma adição de concretude ao estudo da evolução da base de conhecimentos em um setor. Este método pode ser útil, por exemplo, na identificação de descontinuidades nos ciclos de vida de tecnologias, e para classificar as atividades inovativas de acordo com seu 'grau de ruptura'.

A taxa de conectividade assume um papel central na análise da dinâmica da rede e na identificação de diferentes etapas do seu ciclo de desenvolvimento. Geralmente, é medida pelo Indicador de Densidade. A Densidade é definida como o número total de vínculos, expresso como proporção do número máximo possível dada a quantidade de vértices existentes:

$$
\Delta=\frac{l}{\mathrm{n}(\mathrm{n}-1) / 2}
$$

A medida de densidade é uma tentativa de sumarizar a distribuição total de linhas de modo a avaliar quão longe a rede está de sua completude - que ocorre quando todos os vértices são adjacentes. Assim, é um indicador importante na apreciação da evolução da base de conhecimentos em termos da emergência de descontinuidades tecnológicas e da fase subsequente de exploração de trajetórias promissoras de desenvolvimento.

Quando uma descontinuidade emerge, podemos esperar uma queda inicial na Densidade da rede, mas a evolução da sua estrutura é mais difícil de prever. Pode ocorrer uma mudança estrutural, conforme alguns nós desapareçam, outros emerjam e alguns destes últimos se tornem relativamente muito mais importantes que os demais. A evolução de uma rede pode se assemelhar, neste caso, à concentração industrial: em muitos casos a distribuição de centralidade dos nós vai resultar em uma estrutura oligopolista, com alguns poucos vértices estabelecendo muitos vínculos, e com muitos vértices relativamente pouco conectados (KRAFFT ET AL, 2011).

Algumas observações empíricas mostram que, ao longo do tempo, a distribuição de vínculos ao redor dos vértices é muito desigual (SAVIOTTI, 2009), o que significa que, para determinado setor, alguns tipos de conhecimento da sua base são relativamente mais importantes do que outros para empreendimentos inovativos naquele momento.

Uma descontinuidade na base de conhecimentos tem sérias implicações para as organizações que a utilizam. Quão mais dissimilar for o conhecimento em relação ao existente, menor será a capacidade de absorção com base nos seus recursos existentes. Será necessário investir na incorporação de novos recursos, como novas pessoas, com familiaridade com o novo conhecimento. Ademais, um esforço de aprendizado coletivo necessitará ser colocado em prática.

Enquanto a conectividade, medida pela Densidade, descreve a rede como um todo, medidas de centralidade se referem à relevância dos vértices pertencentes à rede. Um ponto pode ser considerado localmente central se ele tem um grande número de conexões com outros pontos no seu ambiente imediato. Já a centralidade global refere-se à proeminência do nó com relação à estrutura da rede inteira.

É importante destacar que há vértices mais incluídos do que outros, ou seja, que são em média mais conectados que os demais. O Indicador de Grau de cada vértice, assim, é uma importante medida da sua centralidade que se refere ao número total de pontos na sua vizinhança. Formalmente, o Grau pode ser representado pela seguinte equação:

$$
\mathrm{D}(\mathrm{v})=\sum_{s \in V_{-}=v} x v s
$$


Para evitar-se o viés causado pelo tamanho da rede, divide-se o grau por seu valor máximo possível:

$$
\mathrm{ND}(\mathrm{V})=\frac{D(v)}{n-1}
$$

Quão maior o Grau dos pontos conectados da rede, maior será a sua Densidade. Quão maior for a Densidade, mais conectada estará a rede, o que significa que mais interconexões estarão sendo exploradas. O Grau é assim a medida mais local de centralidade, já que mede a quantidade de vínculos diretos entre um vértice e os demais. Há outras duas medidas de centralidade: a Proximidade e a Intermedialidade. Neste trabalho, utilizaremos somente a última ${ }^{3}$.

O indicador de Intermedialidade representa a extensão na qual um vértice específico 'reside' entre os demais vértices do gráfico. Ele mede, portanto, a importância relativa de um campo para a conectividade de diferentes segmentos da rede. Este indicador é construído através de uma relação triádica, de modo que um vértice é considerado central para a rede se ele representa um passo obrigatório para se atingir qualquer outro par de vértices. Quão maior for este indicador, maior será a importância do vértice como intermediário para inter-relacionamento indireto entre outros vértices, ou seja, maior será seu potencial para atuar como gatekeeper. Se G for um gráfico com $\mathrm{n}$ vértices, então a Intermedialidade é calculada como:

$$
\mathrm{B}(\mathrm{V})=\sum_{\substack{s_{=v_{=}} \in V \\ s_{-}=t}} \frac{\sigma s t(v)}{\sigma s t}
$$

Onde ost é o número da menor distância geodésica de $\mathrm{s}$ a $\mathrm{t}$, e $\sigma \mathrm{st}(\mathrm{v})$ é o número da menor distância geodésica de $\mathrm{s}$ a $\mathrm{t}$, passando pelo vértice $\mathrm{v}$.

\section{Resultados}

Neste trabalho, concebemos a base de conhecimentos para inovação em renováveis avançados como uma estrutura em rede, formada por diferentes campos (vértices) que formam vínculos (arestas) entre si na construção de soluções tecnológicas.

Utilizamos como proxy para representação dos campos do conhecimento códigos da classificação internacional de patentes (IPCs), cuja co-ocorrência em um mesmo documento representa a formação de um vínculo entre aqueles dois campos ${ }^{4}$. Embora reconheçamos que as patentes exprimem mais o conhecimento dos inventores do que o

\footnotetext{
${ }^{3}$ A Proximidade pode ser definida como a média do inverso da distância geodésica de um vértice em relação a todos os demais da rede. Sua dinâmica, assim, é muito similar à do Grau.

${ }^{4}$ Segundo a Organização Mundial da Propriedade Intelectual (OMPI), "a Classificação, sendo um meio para a obtenção de uma classificação internacional uniforme de documentos de patente, tem como objetivo inicial o estabelecimento de uma ferramenta de busca eficaz para a recuperação de documentos de patentes pelos escritórios de propriedade intelectual e demais usuários, a fim de estabelecer a novidade e avaliar a atividade inventiva ou não obviedade (incluindo a avaliação do avanço técnico e resultados úteis ou utilidades) de divulgações técnicas em pedidos de patente."

Dentre seus propósitos, estão os de "servir como uma base para investigar o estado da técnica em determinados campos da tecnologia" e "servir como uma base para a elaboração de estatísticas sobre propriedade industrial que permitam a avaliação do desenvolvimento tecnológico em diversas áreas". Fonte: OMPI (2015) Guia para a Classificação Internacional de Patentes. Disponível em: http://ipc.inpi.gov.br/ipcpub/static/pdf/guia ipc/br/guide/guide ipc.pdf. Acesso em 20/07/2016.
} 
conhecimento strictu senso (KRAFFT ET AL, 2011), consideramos que a sua utilização para a construção de indicadores para estudo da mudança técnica é útil porque as patentes claramente refletem o comprometimento dos agentes com novas tecnologias e porque contêm uma grande quantidade de informações que estão amplamente disponíveis (GRILICHES, 1990; RAMANI \& LOOSE, 2002).

Para recuperação dos documentos de patentes, realizamos buscas na base Derwent Innovation Index, da Thomson Reuters. Nossa estratégia partiu da formulação de três diferentes queries, das quais apenas uma foi escolhida por sua pertinência. A recuperação dos resultados da busca deu origem a um banco de patentes em renováveis avançados, abrangendo o período 1970-2016, que atualmente conta com 56.135 aplicações. Esta base constitui o banco de dados a partir dos quais as redes representativas da base de conhecimentos foram construídas usando como insumo informações sobre a ocorrência e co-ocorrência de IPCs. Para avaliarmos a dinâmica evolutiva da base de conhecimentos, dividimos a análise em cinco diferentes recortes temporais: 1970-1979; 1980-1989; 1990-1999; 2000-2009; e 2010-2016.

A partir das informações extraídas dos documentos de patente, matrizes de coocorrência de IPCs foram geradas com a utilização do software Vantage Point (versão para estudantes). As matrizes, por sua vez, alimentaram a construção de cinco diferentes redes no software Pajek, que é próprio para a geração dos indicadores de Análise de Redes Sociais descritos na seção anterior. A comparação entre os indicadores gerados para as cinco redes nos permitiu investigar a dinâmica de evolução da base de conhecimentos em renováveis avançados ao longo do tempo.

Neste ponto é preciso ressaltar que existem dificuldades inerentes à definição das fronteiras da base de conhecimentos tecnológicos em qualquer setor, que são reforçadas quando as suas tecnologias se encontram em fases incipientes de desenvolvimento. No que tange à estratégia de busca, isto tem desdobramentos importantes para necessária atenuação do trade-off existente entre a inclusão de tecnologias "intrusas" e a exclusão de tecnologias pertinentes. No entanto, acreditamos que estratégia adotada permite, se não eliminar, ao menos atenuar esta fragilidade.

\subsection{Estrutura da rede}

Nossa análise da evolução da estrutura da rede representativa da base de conhecimentos em renováveis avançados parte da apreciação do padrão de evolução do número de aplicações de patentes em contraposição ao número de classes tecnológicas (IPCs).

Gráfico 1: Patentes vs Número de Classes Tecnológicas (IPCs) 


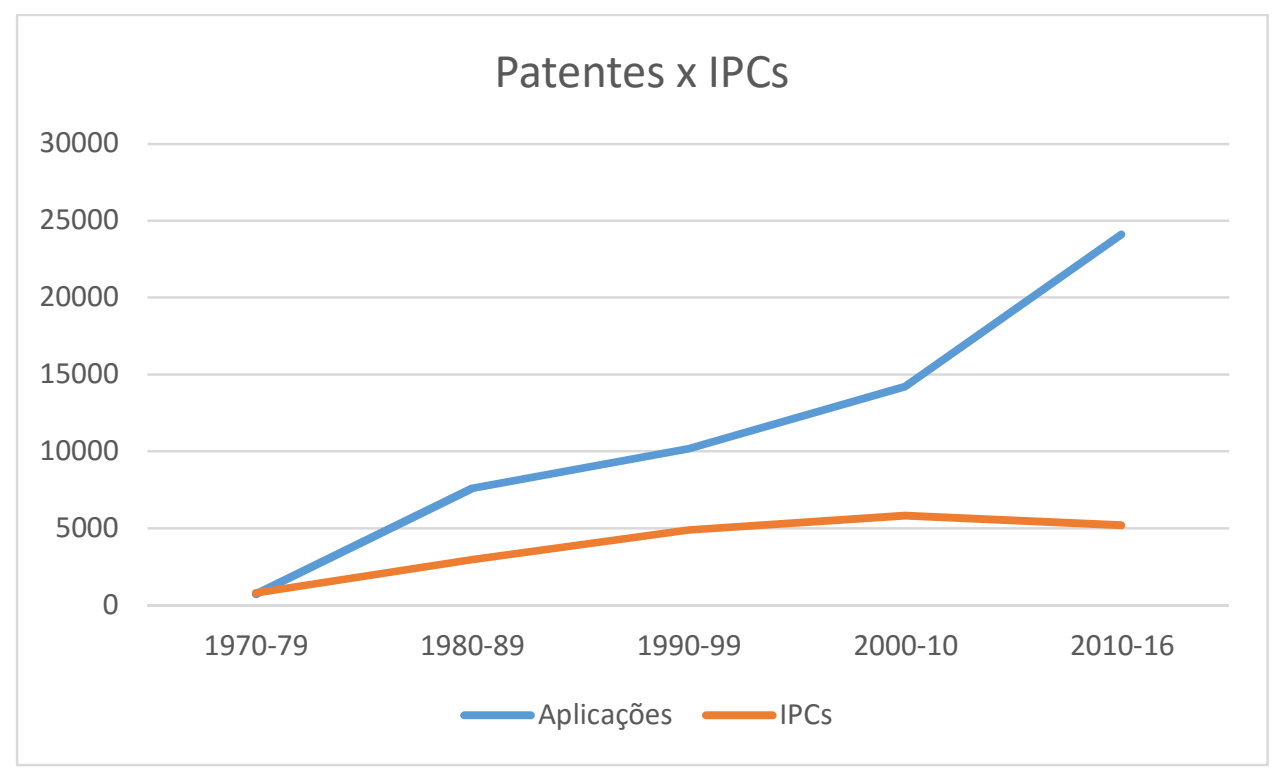

A quantidade de patentes cresce continuamente ao longo do tempo, com diminuição de velocidade no início da década de 80 , contudo, e nova aceleração a partir de 2010. Já o número de IPCs também cresce de 1970 a 1990, mas a uma taxa significativamente inferior. A partir de 1990, este crescimento se dá a uma taxa ainda menor, e há uma inflexão na curva a partir de 2010 - a partir deste ano, até o final do período de análise, há uma queda de $10 \%$ no número de IPCs.

Como consequência desta dinâmica, a relação IPCs / aplicações sofre um grande declínio ao longo do período de análise, de cerca de $80 \%$. De 1970 a 1980, a queda é brusca. Isto se deve especialmente ao rápido aumento do número de aplicações de patentes na década (mais de 1.000\%). De 1980 a 1990, há um pequeno aumento na relação, seguido por uma queda que se acentua a partir de 2000.

O número de classes tecnológicas presente em um portfólio de patentes é uma medida da diversidade de conhecimentos ali presente. Esta é a única conclusão que se pode tirar deste indicador: a de que há um pequeno aumento da diversidade até 2010, com incorporação de novos campos, seguido por uma queda importante no último período de nossa análise. Qualquer outra conclusão derivada somente da análise deste indicador seria precipitada, porque não conhecemos ainda a dinâmica de vinculação entre os campos, nem mesmo a relação hierárquica estabelecida entre eles.

Coma finalidade de analisar de forma mais embasada e concreta a evolução da base de conhecimentos em renováveis avançados, mobilizamos explicitamente ferramentas da Análise de Redes Sociais (ARS) para apreciação: i. da estrutura da base de conhecimentos; e ii. da centralidade relativa dos diferentes campos do conhecimento.

O primeiro destes indicadores, a Densidade da rede, descreve o nível geral de vinculação entre os pontos em um grafo. Este indicador é diretamente dependente do grau de inclusão dos vértices, ou seja, quão menor for a porcentagem de vértices isolados - que não apresentam co-ocorrência com os demais vértices, maior será a Densidade. 
Gráfico 2: Indicador de Densidade, 1970-2016

\section{Densidade}

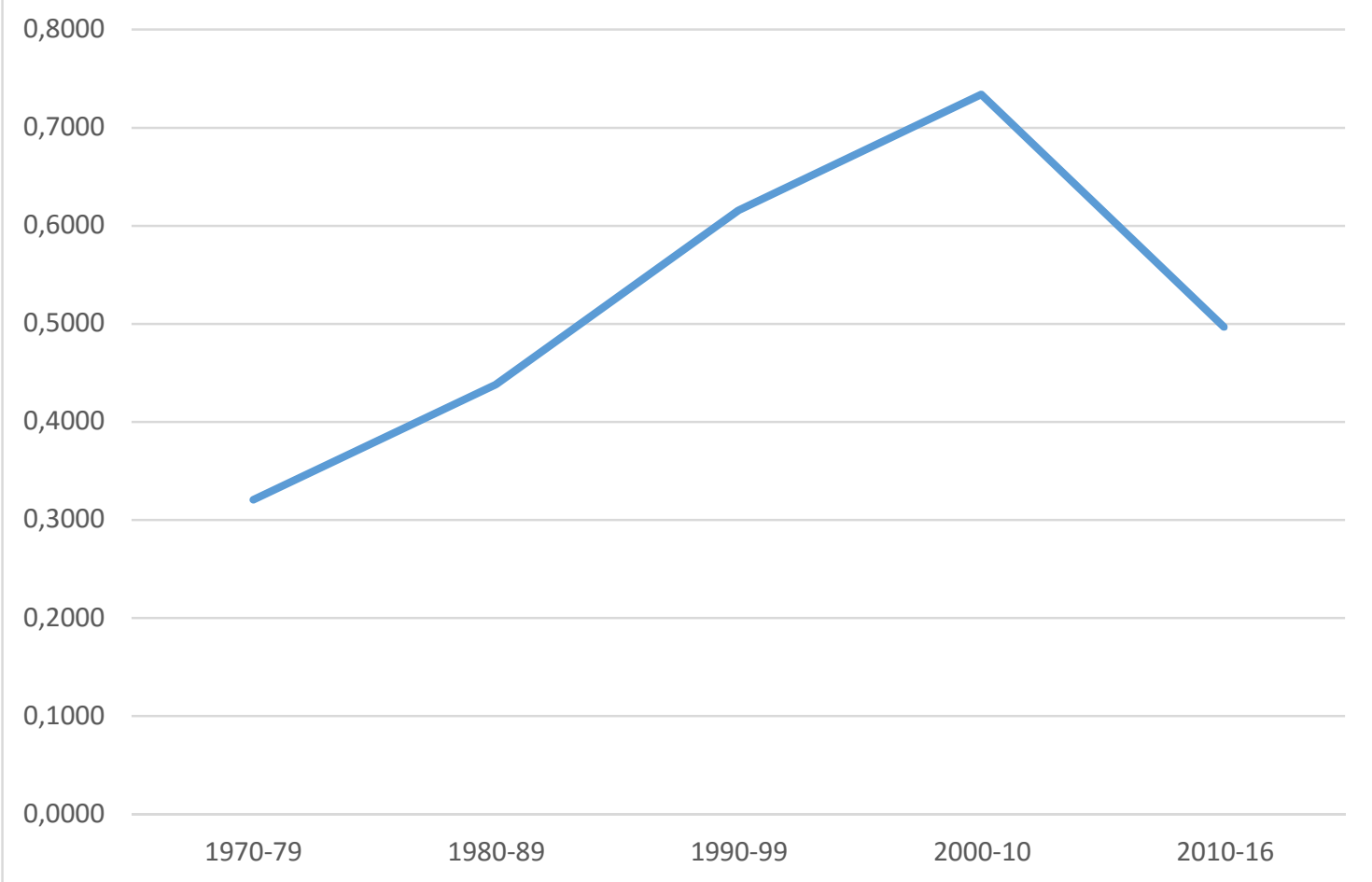

A Densidade para a rede representativa da base de conhecimentos em renováveis avançados sofre um aumento contínuo de 1980 a 2010, sem a presença de descontinuidades importantes.

O aumento do indicador de Densidade indica uma maior taxa de recombinação entre os campos do conhecimento ao longo do tempo. De acordo do padrão esperado de evolução da base de conhecimentos que adotamos, isto significa que a taxa de formação de novos vínculos é superior à taxa de incorporação de novos campos, indicando um período de amadurecimento incremental. A priorização da recombinação de campos já existentes do conhecimento em detrimento da incorporação de novos campos representa um período no qual as empresas estão gerando novas soluções tecnológicas pautadas principalmente na exploração da recombinação entre diferentes campos que já pertenciam à sua base de conhecimentos, ao invés de dirigirem seus esforços para a absorção de novos campos.

Isto é um indicativo de padrão inovativo marcado pela predominância de atividades de busca organizada, voltadas ao desenvolvimento de trajetórias tecnológicas que se mostraram mais promissoras após a descontinuidade representada pelo advento da tecnologia de DNA recombinante na década de 1970, para as quais convergiram muitos dos esforços inovativos.

Já a partir de 2010, a curva de Densidade apresenta uma forte inflexão. Há a partir deste momento uma rápida e forte queda da conectividade da rede, o que indica que a taxa de incorporação de novos vértices passa a ser superior à taxa de criação de novos vínculos. Retomando o resultado anterior, observamos uma queda no número total de campos do conhecimento à qual se soma uma queda da conectividade da rede. Isto 
indica uma mudança no padrão inovativo no setor, com redirecionamento de esforços para a busca exploratória de novas soluções tecnológicas, demandantes de novos conhecimentos e capacidades para a sua exploração, para as quais o conjunto de conhecimentos até então existente não era adequado. Alguns conhecimentos, obsoletos, deixam de ser utilizados em atividades inovativas. Outros emergem e ganham importância. Por estarem ainda fracamente vinculados aos demais, a conectividade da rede cai.

A queda da conectividade pode ser confirmada pela análise do Grau Médio, ou seja, o nível médio de vinculação dentre os vértices.

Gráfico 3: Grau Médio, 1970-2016

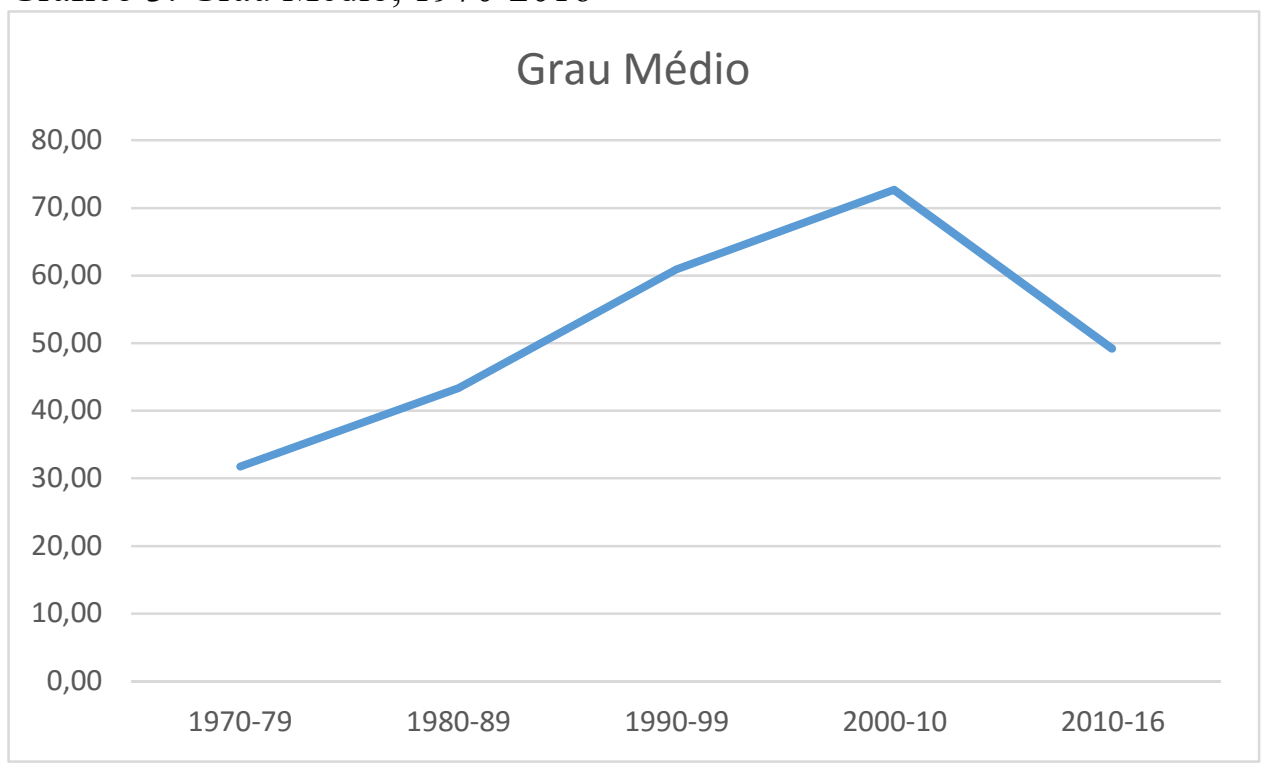

A dinâmica que descrevemos até aqui representa uma mudança fundamental que ocorre no padrão de desenvolvimento da base de conhecimentos entre os dois últimos períodos de nossa análise. Esta mudança, em nosso entendimento, está relacionada à busca de novas soluções tecnológicas para os desafios de grande monta que emergiram durante o escalonamento das primeiras tecnologias voltadas à produção de renováveis avançados, em especial de biocombustíveis celulósicos. Para sua sobrevivência, as empresas passaram a buscar a penetração em novos mercados, a partir do desenvolvimento de novas aplicações comerciais para seus produtos, ou novas tecnologias capazes de sanar os problemas encontrados no decorrer do desenvolvimento de seus pacotes tecnológicos.

A busca pela superação destes grandes desafios exigiu a absorção de conhecimentos tecnológicos que ainda não faziam parte da sua base, resultando na queda da densidade e grau médio.

4.2 Centralidade dos campos do conhecimento 
A inflexão na curva destes dois indicadores relacionados à estrutura da rede na passagem do penúltimo para o último período de nossa análise nos leva ao seguinte questionamento: quais são as classes emergentes que, por estarem ainda fracamente conectadas às demais, levaram a uma queda na conectividade da base?

\subsubsection{Frequência de ocorrência}

Analisando a composição da rede representativa do período 2000-2009 em comparação àquela para 2010-2016, há 8 classes que nos chamam atenção pelo expressivo aumento em sua ocorrência relativa. São estas:

a. Produção de compostos pela ação da carboidrase (C12P-019/14).

b. Gorduras, Óleos graxos, Ceras tipo éster, Ácidos graxos superiores e Óleos ou gorduras oxidados (C12P-007/64)

c. Preparação de hidrocarbonetos acíclicos (C12P-005/02)

d. Compostos monossacarídeos (C12P-019/02)

e. Enzimas agindo sobre ligações beta-1, 4-glicosídicas, p. ex. celulase $(\mathrm{C} 12 \mathrm{~N}-009 / 42)$

f. Vetores ou sistemas de expressão especialmente adaptados à E.coli (C12N-015/70);

g. Saccharomyces cerevisiae (C12R-001/865)

h. Liases (C12N-009/88).

Gráfico 4: Ocorrência normalizada, IPCs selecionados

\section{Ocorrência normalizada, IPCs emergentes}

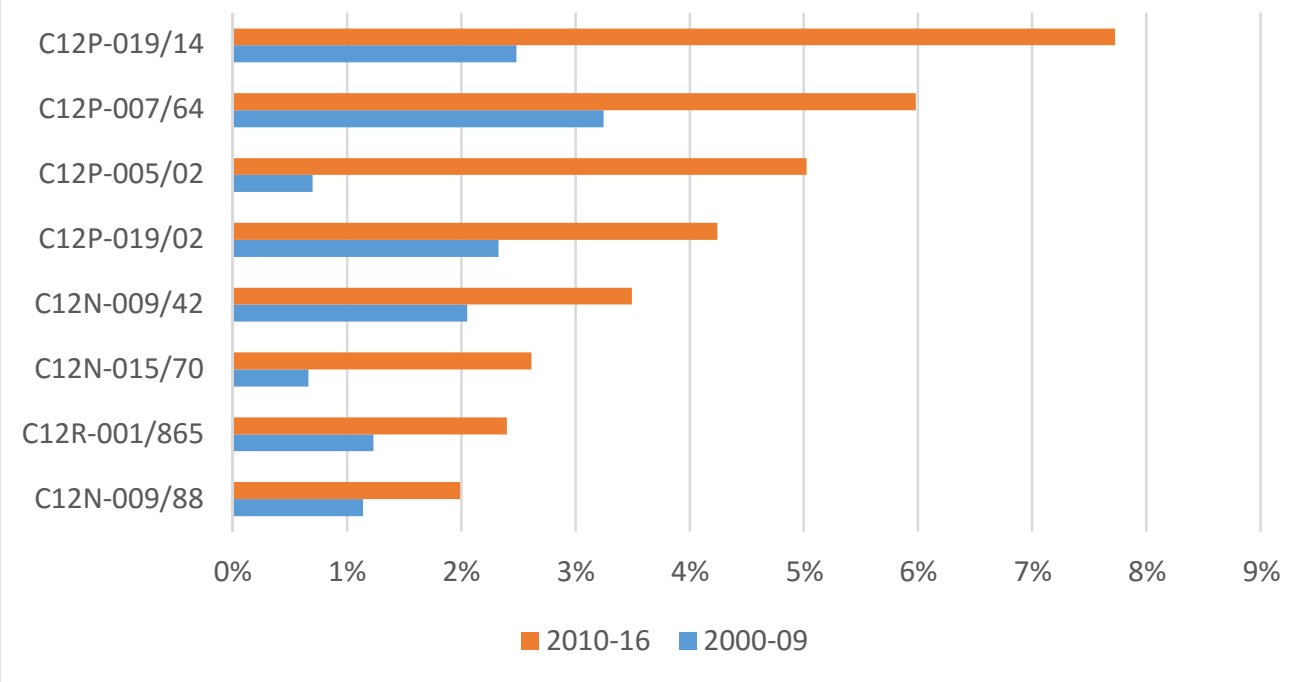

As classes C12P-019/14, C12N-009/42 e C12N-009/88 são todas referentes ao desenvolvimento de novas enzimas. A produção de complexos enzimáticos de alta eficiência e de baixo custo é um dos principais gargalos ao desenvolvimento da 
produção de biocombustíveis e bioprodutos avançados. Enzimas são utilizadas para a conversão de carboidratos complexos encontrados na biomassa, como a celulose e a hemicelulose, em açúcares fermentáveis. Embora grande parte do mercado mundial de enzimas esteja sob controle de corporações grandes e globalmente estabelecidas, como DuPont, Novozymes e DSM, há muitas startups surgindo a partir de oportunidades emergentes com o avanço científico. Podemos citar, por exemplo, as estadunidenses Elemental Enzymes e CinderBio, e a holandesa Clea Technologies.

A classe $\mathrm{C} 12 \mathrm{P}-007 / 64$, por sua vez, está relacionada à produção de ácidos graxos utilizados como insumos para cosméticos, especialidades químicas ou aditivos alimentícios, frequentemente a partir da utilização de microalgas. $\mathrm{O}$ aumento na ocorrência desta classe está relacionado à mudança de foco que muitas empresas do setor têm empreendido, deslocando-se do desenvolvimento da produção em grande escala de biocombustíveis para a produção de compostos com alta margem e pequeno volume, a partir de uma estratégia de diversificação pautada no aproveitamento de economias de escopo.

Já a classe C12P-005/02 está relacionada ao desenvolvimento de tecnologias de conversão baseadas na gaseificação da matéria-prima, principalmente resíduos urbanos (municipal solid waste-MSW) e resíduos florestais, muito comuns na indústria de papel \& celulose. O aumento da importância destas tecnologias está vinculado ao alargamento de alguns gargalos que até então dificultavam a sua utilização. Estes avanços estão relacionados a aprimoramentos na nas tecnologias de fermentação do gás de síntese (como o desenvolvimento de microrganismos tolerantes a condições 'ambientais' extremas) e ao escalonamento de tecnologias como o processo FischerTropsch.

Por fim, a classe C12R-001/865 está vinculada ao melhoramento genético de fungos, em especial da espécie Saccharomyces cerevisiae, utilizados principalmente na produção de amido, insumos químicos (como ácido biosucínico) e nutracêuticos. Já a classe $\mathrm{C} 12 \mathrm{~N}-015 / 70$ representa novas técnicas para o melhoramento genético da bactéria $E$. Coli, que consistem da introdução de elementos exógenos para reprogramála com a finalidade produzir novos compostos químicos (como o isopreno ou ácidos graxos).

Agora passamos à análise da importância relativa dos diversos campos que compõe a base de conhecimentos em renováveis avançados.

\section{i. Grau}

O Grau mede a quantidade de vértices à qual um vértice está diretamente conectado, sendo considerado o principal indicador de centralidade local. Segundo este indicador, dentre as classes mais centrais estão aquelas vinculadas à manipulação genética de bactérias: C12N-001/20 (que é a principal classe em todo o período), C12R-001/01 e $\mathrm{C} 12 \mathrm{~N}-001 / 21$. Isto representa uma recombinação crescente destas classes com as demais tecnologias que compõe a base de conhecimentos. C12N-001-20 é o principal IPC desde 1970, e apresenta um aumento de $49 \%$ no seu Grau ao longo do período analisado; já C12R-001/01 e C12N-001/21, respectivamente, apresentam um incremento de $66 \%$ e $43 \%$ em seu Grau. 
Gráfico 6: Evolução do indicador de Grau para IPCs selecionados

Tecnologias envolvendo bactérias - Grau

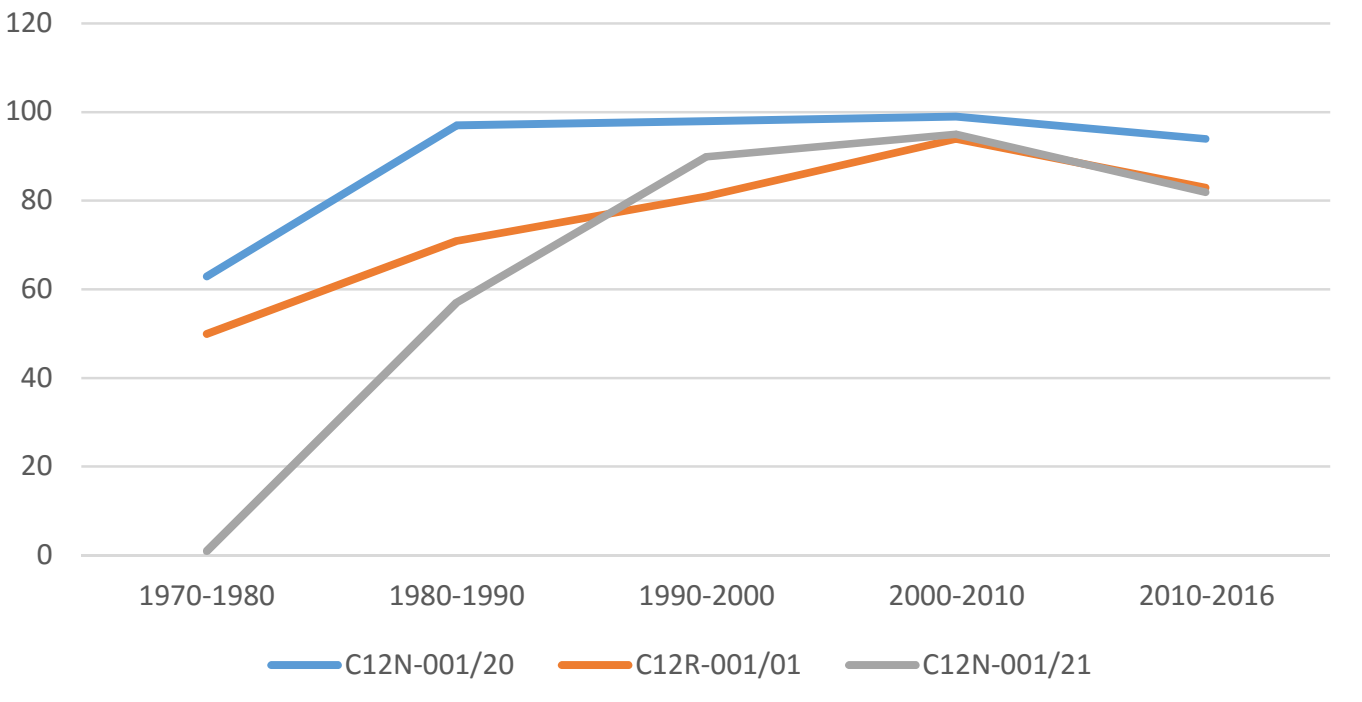

De 1970 a 2016, as classes que apresentam maior crescimento deste indicador são as seguintes: C12P-007/06 (Preparação de compostos orgânicos contendo oxigênio contendo um grupo hidroxila - acíclico - Etanol), com crescimento de 458\%; C12P019/14 (Preparação de compostos contendo radicais sacarídeos produzidos pela ação de carboidrase, p. ex. por alfa-amilase), com crescimento de 150\%; e C12N-001/16 (Micro-organismos - Fungos - Leveduras; Seus meios de cultura), com crescimento de $108 \%$.

No entanto, é interessante notar como muitas das classes que mencionamos perdem importância medida pelo Grau quando restringimos a análise a apenas os dois últimos períodos. É o que acontece, por exemplo, com todas aquelas classes emergentes identificadas na seção anterior. Isto sugere que estes campos têm passado por uma revolução interna, com um rápido aumento na geração de novas soluções que tem ocorrido, contudo, sem que haja a sua recombinação com outros campos estabelecidos, levando a uma queda na conectividade da rede. Espera-se que a recombinação ocorra quando houver o redirecionamento de esforços para a busca organizada por novas soluções tecnológicas que incorporem estes novos conhecimentos, levando a um aumento da conectividade da rede decorrente de um novo padrão setorial de inovação. 
Gráfico 5: Grau, IPCs selecionados

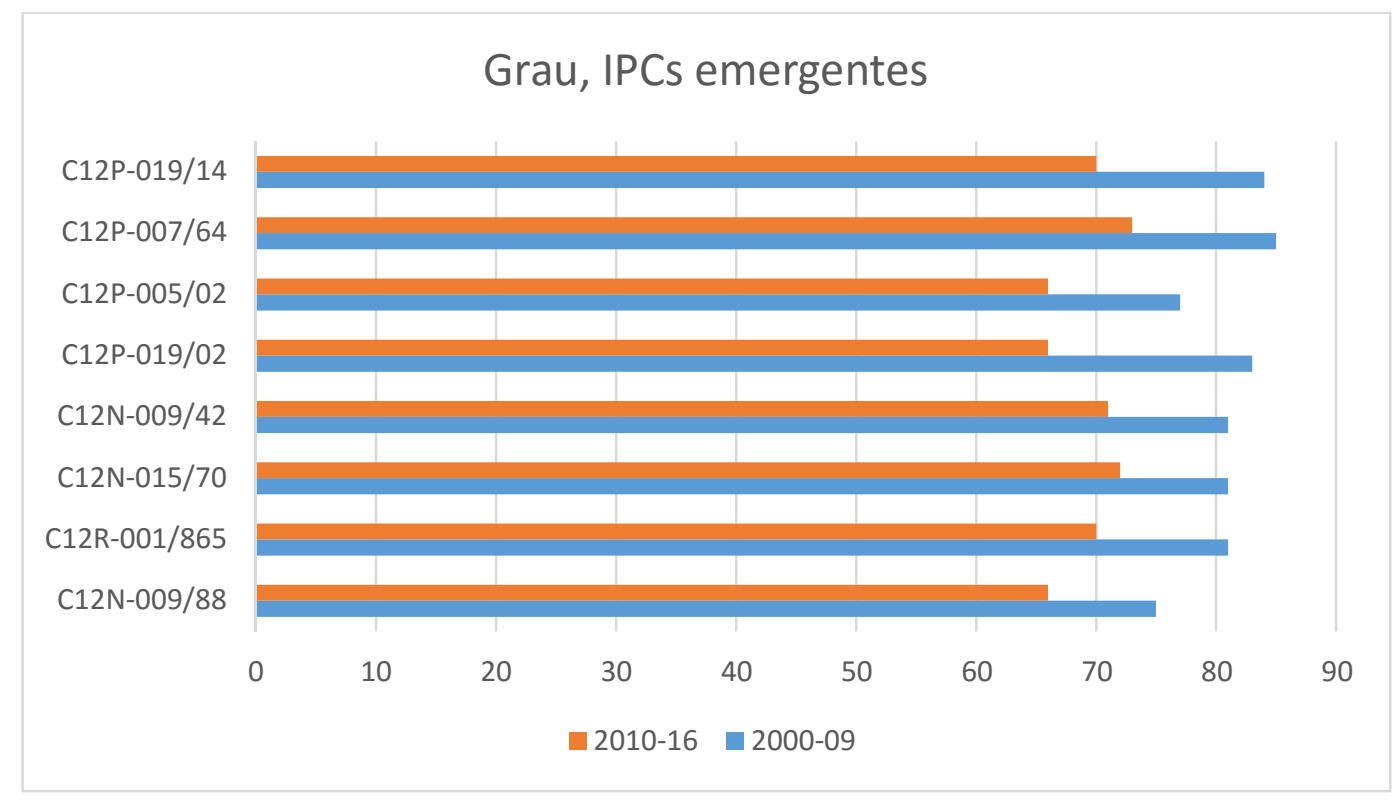

\subsubsection{Intermedialidade}

Enquanto o Grau enfatiza a importância local do vértice - ou seja, o quão conectado está um vértice em relação aos pontos imediatamente vizinhos a ele, o indicador de Intermedialidade enfatiza a importância global do vértice para a rede, uma vez que mede o quão presente um vértice está entre os caminhos que vinculam indiretamente segmentos distantes da rede. Em outras palavras, este indicador mede a capacidade de um campo em atuar como gatekeeper.

Os campos referentes à manipulação genética de bactérias continuam sendo os mais centrais pelo indicador de Intermedialidade: C12N-001/20 é o principal, mas sofre uma perda de cerca de $12 \%$ em seu potencial de intermediação no período analisado. Já o campo C12R-001/01 apresenta um aumento de 33\% no indicador durante o período analisado, enquanto que $\mathrm{C} 12 \mathrm{~N}-001 / 21$ experimenta um aumento de $108 \%$.

Em geral, os principais aumentos do índice de Intermedialidade no período estão concentrados no campo C12P (tecnologias relacionadas à fermentação). Especialmente, C12P-007/06 (produção de etanol), tem um aumento de $1735 \%$ ao longo de todo o período de análise (84\% de aumento entre 2010 e 2016), enquanto que C12P-019/14 (preparação de compostos com uso de enzimas) sofre aumento de 346\%, e C12P-007/10 (etanol celulósico), de $58 \%$. Isto indica o grande potencial que estas classes desenvolveram ao longo do tempo de atuarem como elos entre segmentos da rede que não possuem ligação direta entre si. 
Gráfico 7: Indicador de Intermedialidade, Classe C12P, 1970-2016

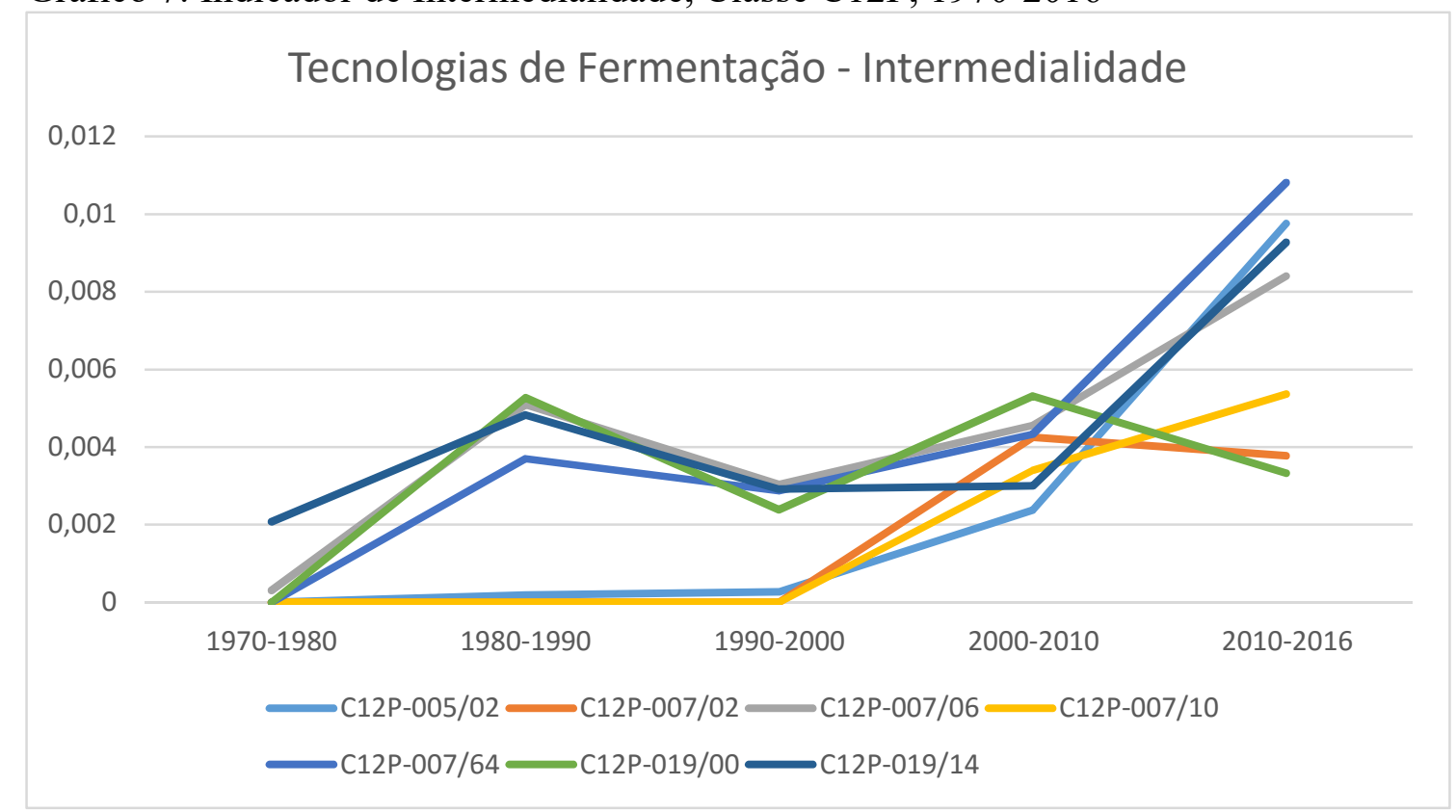

No entanto, quando comparamos apenas os dois últimos períodos, os maiores crescimentos da Intermedialidade são dos seguintes campos: aparelhos para enzimologia ou microbiologia (C12M-001/00), com aumento de 516\%; preparação de hidrocarbonetos acíclicos (C12P-005/02), aumento de 311\%; tecnologias envolvendo bactérias (C12R-001/01, C12N-001/20 e C12N-001/21), com aumento médio de 216\%; e tecnologias envolvendo fungos (C12N-001/16, C12N-001/14 e C12R-001/645), aumento médio de $199 \%$.

Os campos que mais perdem capacidade de atuar com intermediadores durantes os dois últimos períodos são: preparação de compostos contendo radicais sacarídeos (C12P-019/00) - (queda de 37\%), e compostos contendo duas ou mais unidades mononucleotídicas tendo grupos fosfato ou polifosfato separados $(\mathrm{C} 07 \mathrm{H}-021 / 04)$, com perda total desta capacidade.

Os indicadores que construímos a partir da ocorrência e co-ocorrência de IPCs, especialmente aqueles derivados do ferramental de Análise de Redes Sociais, nos permitem concluir que, ao longo do período abrangido pela pesquisa, há mudanças importantes tanto com relação à estrutura da base de conhecimentos em renováveis avançados, como com relação à centralidade relativa dos diferentes campos que a compõe. Há, no entanto, uma certa estabilidade na composição da rede, com a persistência de algumas tecnologias-chave ao redor das quais há uma dinâmica de emergência e desaparecimento de outras classes, o que reflete o alto custo de se alterar a base de conhecimentos, o que só ocorre, portanto, de maneira gradual e incremental. Estas tecnologias-chave são: manipulação genética de bactérias (C12N-001/20 e C12R001/01); e manipulação genética de fungos (C12N-001/14). 


\section{Discussão e Conclusões}

O objetivo desta pesquisa foi o de compreender como a base de conhecimentos da indústria de renováveis avançados se desenvolveu nos últimos 46 anos, tanto em termos da sua estrutura como da importância relativa dos diversos campos que a compõe. Como argumentamos, a indústria tem enfrentado sérios desafios à sua consolidação, o que tem levado as empresas a redefinirem suas estratégias tecnológicas, com importantes impactos sobre os conhecimentos relevantes para suas atividades inovativas.

Podemos dizer, a partir dos indicadores de Densidade e Intermedialidade, que a base de conhecimentos em renováveis avançados passou por um longo período de amadurecimento, traduzido no seu adensamento e ganho de complexidade, que se inicia com a descoberta da tecnologia de DNA recombinante na década de 1970 e vai até 2010. A partir deste ano, no entanto, estes indicadores apontam um padrão de inovação setorial de natureza diferente, com forte queda na conectividade na rede relacionada à incorporação de novos conhecimentos. Em nosso entendimento, este movimento é consequência do redirecionamento estratégico que muitas empresas adotaram em face aos enormes desafios encontrados no escalonamento de suas tecnologias, o que foi agravado pela queda do preço internacional do petróleo nos últimos anos. Esta mudança está relacionada não apenas à alteração na frequência de ocorrência dos muitos campos que compõe a base, mas também à alterações na sua centralidade relativa, como nos mostra a análise dos indicadores de Grau e de Intermedialidade.

Seria possível argumentar que o padrão de inovação predominante identificado, referente ao período 1970-2010, representa a construção de algo próximo ao que concebemos como o Marco II schumpteriano, marcado pela prevalência de grandes empresas, com atividades inovativas apoiadas em fortes competências de P\&D e no uso de ativos complementares. No entanto, esta caracterização depende do estudo das fontes de oportunidades tecnológicas, do regime de apropriabilidade e de quão cumulativa é a construção do conhecimento, algo que será realizado em pesquisas futuras.

É importante salientar que, embora tenha sofrido mudanças fundamentais ao longo do tempo, a base de conhecimentos para atividades inovativas em renováveis avançados é marcada por certa estabilidade, ou seja, há classes que se mantém dentre as mais importantes ao longo de todo o período, como aquelas relacionadas à manipulação genética de bactérias e de fungos. Ao redor destas classes, contudo, há uma dinâmica de aparecimento e desaparecimento de outras classes.

Por fim, gostaríamos de ressaltar que esta é uma pesquisa ainda em progresso. Embora a metodologia utilizada tenha demonstrado ser uma promissora ferramenta para o estudo da dinâmica evolutiva do conhecimento tecnológico, seu uso com esta finalidade ainda é muito incipiente. Deste modo, outras pesquisas serão necessárias para reforçar, validar ou refutar os resultados obtidos. 


\section{Referências Bibliográficas}

ANTONELLI, C; KRAFFT, J. \& QUATRARO, F. (2010) RECOMBINANT KNOWLEDGE

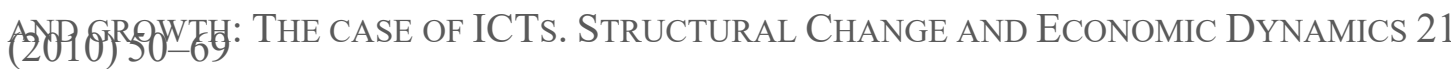
BRESCHI, S., LISSONI, F. \& MALERBA,F. (2003) KNOWLEDGE-RELATEDNESS IN FIRM TECHNOLOGICAL DIVERSIFICATION. RESEARCH POLICY 32 (2003) 69-87

DOSI, G., NELSON R. AND WINTER S.G.(EDS.) (2000). THE NATURE AND DYNAMIC of Organizational CAPABILITIES. OXford/NeW York, OXFord UniVERSITY Press

GRILICHES Z. (1990), PATENT STATISTICS AS ECONOMIC INDICATORS : A SURVEY, JOURNAL OF ECONOMIC LITERATURE,

$27: 1661-1707$.

KLEVORICK, A; LEVIN, R.; NELSON, R. \& WINTER, S. (1995) ON THE SOURCES

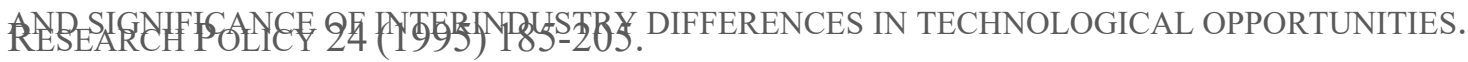

KRAFFT, J. QUATRARO, F. \& SAVIOTTI, P. (2011): THE KNOWLEDGE BASE EVOLUTION IN BIOTECHNOLOGY: A SOCIAL NETWORK ANALYSIS, ECONOMICS OF INNOVATION AND NEW TECHNOLOGY, 20:5, 445-475

LEVITT, B. \& MARCH, J. (1988) ORGANIZATIONAL LEARNING. ANNUAL REVIEW OF SOCIOLOGY, VOL. 14. (1988), PP. 319-340

MALERBA \& ORSENIGO (1997) TECHNOLOGICAL REGIMES AND SECTORAL PATTERNS of INNOVATIVE ACTIVITIES. INDUSTRIAL AND CORPorATE CHANGE. Volume 6, Number $1,1997$.

MOLCHANOV (2015) AdVANCED BioeCONOMy CONFERENCE Highlights: ScAle-Up, Strategics, Sustainability. Alternative EnERgy AND Clean TECHNOlOgY FUELS AND CHEMICALS: INDUSTRY TIDBIT.

NAMEROFF, T.; GARANT, R. \& ALBERT, M. (2004) ADOPTION OF GREEN CHEMISTRY: AN ANALYSIS BASED ON US PATENTS. RESEARCH POLICY 33 (2004) 959-974

Nascimento et al (2003). TeCnOlogia do DNA Recombinante. Apostila dA FACUldade de MEdicina da USP. RibeirÃo Preto, São PAUlo.

NESTA, L. \& SAVIOTTI, P.P. (2005) COHERENCE OF THE KNOWLEDGE BASE AND THE Firm's InNOVATIVE PERFormance: EVIDENCE From the U.S. PHARMACEUTICAL Industry. THE JournAL Of IndUSTRIAL ECONOMICS, VOL. 53, No. 1 (MAR., 2005), PP. 123-142

NOOY, W., MRVAR, A. \& BATAGELJ (2005) EXPLORATORY SOCIAL NETWORK Analysis with Pajek. CAmbridge University Press, New York: NeW York.

OECD (2011) SUSTAINABLE CHEMISTRY: EVIDENCE ON INNOVATION FROM PATENT DATA. SERIES ON Risk MANAGEMENT, N. 25. PARIS, 28/FEV/2011. 
OrganiZAÇ̃̃o Mundial de Propriedade Intelectual (2015) GuiA PARA A CLASSIFICAÇÃo INTERNACIONAL DE PATENTES. DiSPONÍVEL EM:

HTTP://IPC.INPI.GOV.BR/IPCPUB/STATIC/PDF/GUIA_IPC/BR/GUIDE/GUIDE_IPC.PDF. ACESSO EM 20/07/2016

PAPOUTSAKIS, E.T. (2015) RE-ASSESSING THE PROGRESS IN THE PRODUCTION OF ADVANCED BIOFUELS IN THE CURRENT COMPETITIVE ENVIRONMENT AND BEYOND: WHAT ARE THE SUCCESSES AND WHERE PROGRESS ELUDES US AND WHY. IND. ENG. CHEM. RES., 2015, 54 (42), PP 10170-10182.

QUATRARO, FRANCESCO (2009) EVOLUTION OF THE KNOWLEDGE BASE IN KNOWLEDGE INTENSIVE SECTORS. PAPER PRESENT AT DRUID SUMMER CONFERENCE, CBS - COPENHAGEN BUSINESS SCHOOL.

RAMANI, SHYAMA \& LOOSE, MARIE-ANGELE DE (2002). USING PATENT STATISTICS AS KNOWLEDGE BASE INDICATORS IN THE BIOTECHNOLOGY SECTORS: AN APPliCATION to France, Germany AND the U.K. SCIENTOMETRICS, Vol. 54, No. 3 (2002) 319-346.

SAVIOTTI, P.P. (2004) THE KNOWLEDGE-BASE OF THE FIRM IN BIOTECHNOLOGY BASED SECTORS: PROPERTIES AND PERFORMANCE. REVISTA BRASILEIRA DE INOVAÇÃO (RBI) V. 3, N. 1 JAN/JUN (2004).

SAVIOTTI, P.P. (2007) ON THE DYNAMICS OF GENERATION AND UTILIZATION OF KNOWLEDGE: THE LOCAL CHARACTER OF KNOWLEDGE. STRUCTURAL CHANGE AND ECONOMIC DYNAMICS 18 (2007) 387-408

SAVIOTTI, P.P. (2009) KNOWLEDGE NETWORKS: STRUCTURE AND DYNAMICS, IN A. PYKA, A. SCHARNHORST (EDS.), INNOVATION NETWORKS, UNDERSTANDING COMPLEX SYSTEMS, SPRINGER-VERLAG BERLIN HEIDELBERG 2009

SCHUMPETER, JOSEPH A. (1911). A TEORIA do DESENVOLVIMENTO ECONÔMICO. SÃO PAulo: Abril CUltural, 1982.

SCHUMPETER, Joseph A. (1942). CAPITALISMO, SOCIALISMO E DEMOCRACIA. Rio DE JANEIRO: ZAHAR, 1984.

U.S. ENERGY INFORMATION AdMINISTRATION (2016) SHORT-TERM ENERGY OUTLOOK (STEO).

TEECE, D.; RUMELT, R.; DOSI, G. \& WINTER, S. (1994) UNDERSTANDING CORPORATE COHERENCE. THEORY AND EVIDENCE. JOURNAL OF ECONOMIC BEHAVIOR AND ORGANIZATION 23 (1994) L-30. NORTH-HOLLAND 